this is the only way to arrive at an accurate opinion on the subject.

It may be a nodule in the breast is caused by sarcoma; if so, the sooner it is remored the better; it may be cystic, but tumours of this description are seldom met with unless in conjunction with sarcomas or in carcinomas. Should the nodule have formed before the patient had reached her thirtieth year of age, it is not likely to be cancer, more probably it is an adeno-fibroma. These tumours are usually single, peripheral, and more mobile in the gland than carcinomas; but if in doubt we must make an incision into the growth. Should nothing more be necessary the wound may be closed, it will heal in the course of a week or ten days; on the other hand, if we wait and watch the suspected tumour until it is so far developed as to render the diagnosis certain, supposing it to be cancer, we shall have waited too long, the time will have passed when we might possibly hare sared the patient from one of the most terrible deaths to which a human being can be subjected. It is well to bear in mind the fact, that cancer occurring in patients from 30 to 50 years of age, form by far the greater number of tumours of the breast we meet with in practice, and that every one of them has had a beginning.

In conclusion, we can safely answer the question referred to at the commencement of my last lecture in the affirmative; modern improvements in surgery enable us to modify the rules laid down fifty years ago as to the desirability of excising carcinomata of the breast, because the risk to life from such an operation has been lessened, and, further, the system of dressing wounds has much diminished the pain of tho after-treatment. But what I wish particularly to impress on those of you who intend to follow general practice' is not to procrastinate or shirk your responsibility when consulted by a patient suffering from a persistent hard nodule in the breast. It may be, and indeed is, often necessary to clear up any uncertainty that exists in your minds as to the nature of the growth by means of the knife; should the nodule then seem to be a carcinoma excise the entire gland. You may thus save some of your patients from the further development of the disease, and you will certainly lessen their sufferings and prolong life.

\section{ON BONE-SETTING.'}

BY W. J. PEN.YY, F.K.C.S., Assistant-Surgeon to the Bristol General Hospital; Demonstrator of Anatomy
to the Bristol Medical Schiool.

Mr. President and Grntlenen,-I am obliged to you for the compliment you have paid me, in asking me to open the discussion this evening. The subject selected is more complicated than appears at first sight. The time at our disposal will not allow me to enter into it as fully as I should wish, but I will endearour to bring its principal features before you as clearly and briefly as possible.

Bone-setting commonly so-called, means not a setting of fractured bones, but the term has arisen from the erroneous view imparted by quacks to the general public, that in many cases of distorted and useless joints a bone is out and requires setting in place again. This setting consists of some forcible movement, during which a crack is usually elicited. This crack is supposed to be caused by the bone slipping back into its place. Among affections successfully treated in this way are cases of fibrous adhesions within and around the joint ligaments and synovial membranes; cases of true complete dislocation; cases of partial dislocation or subluxation; cases of adhesion of tendons to each other, or to ligaments or other structures; disarrangement of ligaments; displacement of tendons; hysterical affections ; cases of muscular spasm; ganglia which have been ruptured.

In some cases, bodies foreign to the part, such as new growths, detached pieces of cartilage, displaced cartilages, thickened synovial fringes, organised blood-clot, and numerous others, have become nipped between the bones forming a joint, and have thus interfered with its functions.

Not infrequently inflamed or strumous joints, or even malignant enlargements, have been treated in the same manner; I need hardly tell you with what results. I have seen three cases of amputation from improper use of these forcible movements.

Bono-setting has been little studied by the legitimate members

1 Rend before the West Somernet Branch of the British Medical Associatlon. of our profession, and as cases amenable to treatment are common, quacks and charlatans have had an extensive field for their operations. Many of these quacks, especially one lately deceased, have acquired considerable skill in the treatment of these cases, and no small reputation from the good results they have obtained. The majority, however, have little knowledge of the subject, and consequently have numerous failures as well as successes. The public do not fail to laud the cures obtained by these men, or women, especially when properly qualified surgeons have previously failed to cure the complaint; and they seem rather pleased to have the chance of "having a slap" at their regular attendant. On the other hand, if a bad result ensues, they are ashamed to confess their lack of faith in their own surgeon, and dislike having the laugh turned against themselves; consequently we hear little of the bad results. Many of these quacks do not even know the anatomy of the parts affected, let alone the pathology ; their knowledge as a rule amounts to this-" Here is a stiff joint, it must be worked." They know that the majority of cases are improved, a small proportion are made worse. If a bad result ensues, they frequently lay the blame on the previous attendant, by saying to the patient-" You should have consulted me before, and you would not have come to this." The more brazen their assertions, the more easily are they swallowed by the majority of the British public, who apparently like to be gulled.

Now, gentlemen, I hold it is our duty to beat these quacks on their own ground. The public are perfectly within their right to get cured wherever they can. They do not care, and why should they, whether the cure is wrought by a Member of the College of Surgeons, or by the village blacksmith, with a strong arm and a taste for backing his muscular powers against the stiffness of the patient's joint. They want relief from their ailments, and do not consider they have any special call to maintain Members of the College of Surgeons, if they cannot cure them. It is, however, our duty to expose these ignorant pretenders on all occasions ; they do not spare our reputations, we need not consider theirs. It does not do simply to abuse them as impostors; patients, not unnaturally, judge by results; we must recognise the fact that they often cure cases in which we have failed. It appears to me that very often we treat the cases just long enough to make them fit for the bone-setter, and then, sometimes from lack of patience on the part of the sufferer, sometimes from lack of enterprise on the part of the surgeon, they drift into the hands of these quacks and get cured. The only way in which we can hope to compete successfully with these men is by a careful study of the anatomical, clinical, and pathological conditions associated with these affections. Haring thus gained a sounder knowledge than they, and not fearing to act on it, our successes will prove to our patients that properly qualified scientific men are the more trustworthy, more likely to effect a cure and less likely to aggravate the complaint. I will take as my text the following anecdote.

My father, many years ago, had a valuable horse, which fell and cut one knee badly. The joint was opened. For many weeks it was under the care of a veterinary surgeon with a good reputation. After a time the joint, which had been enormously swollen and discharged pus freely, subsided, and the wound healed. The horse had a stiff knee. "Turn it out to grass for three months," said the vet.; this was done. At the end of that time there was only a slight blemish on the knee, it was the same size as the other, but the horse was perfectly useless for driving, as the knee was still stiff and the horse extremely lame. The vet. then gave up the case in despair, and my father, in disgust, sold the animal for a very small sum. Lo and behold within a day or two the new owner getting impatient at the horse's slow progress, gave it a smart cut with a whip; the animal, a well-bred spirited beast, plunged forward, and from that minute lost its lameness, and went as well as ever. I have seen it many times since, and it has never been lame. A great many lessons can be learnt from that case. A few flbrinous adhesions must have existed, probably within the joint. The pain caused by them prevented the horse, though spirited, from bending the knee; the sudden plunge caused by the whip ruptured them, and the horse was cured. They may have been no larger than threads of cotton. The structures round and in the joint were free from inflammation, and the constitution was sound; a typical example of the cases suitable for bone-setting. My father, a man of common sense, naturally wished to know why the veteriaary could not have foreseen this; he now has less faith in him than formerly, and I almost fancy that, in spite of the empirical treatment of the other man, he would prefer his opinion in a similar case, and the result justifles this. 
If this horse had been a man, it is not at all unlikely he would have been treated in a similar fashion. The surgeon in attendance, recognising the danger of exciting inflammatory mischief in the joint, might not have cared to adopt such energetic treatment. The patient might then have drifted into the hands of a bone-setter, entirely ignorant of pathology, who would have told him "the bone was out," given the joint a wrench, ruptured the adhesions, and the case would have been cured. The original attendant, who had brought the case safely through the dangers of a wound of a large joint, would not only have lost all credit for that, but would have been considered less competent than the quack ; I do not think we can say quite without reason.

A very short time ago I broke down, almost with a couple of fingers, some adhesions in the shoulder-joint of a man who had been unable to use his arm properly for ten years. Before the operation, if the scapula were fixed, the arm could only be moved one inch away from the side. The patient had been in the habit of pressing his elbow firmly against his side, by this manœurre saving the strain on the shoulder-adhesions when he worked the hand. The day after the manipulation he could easily move the arm six inches from the side, and he is now progressing satisfactorily towards recovery. The adhesions were very slight, and no perceptible inflammatory mischief was excited by the operation. He had consulted several surgeons, all of whom had failed to treat the case sufficiently freely. There was marked muscular spasm, which made the ankylosis more apparent; this, of course, disappeared under chloroform, and rendered the rupture of the adhe sions a very simple matter. I hope to publish this case later on.

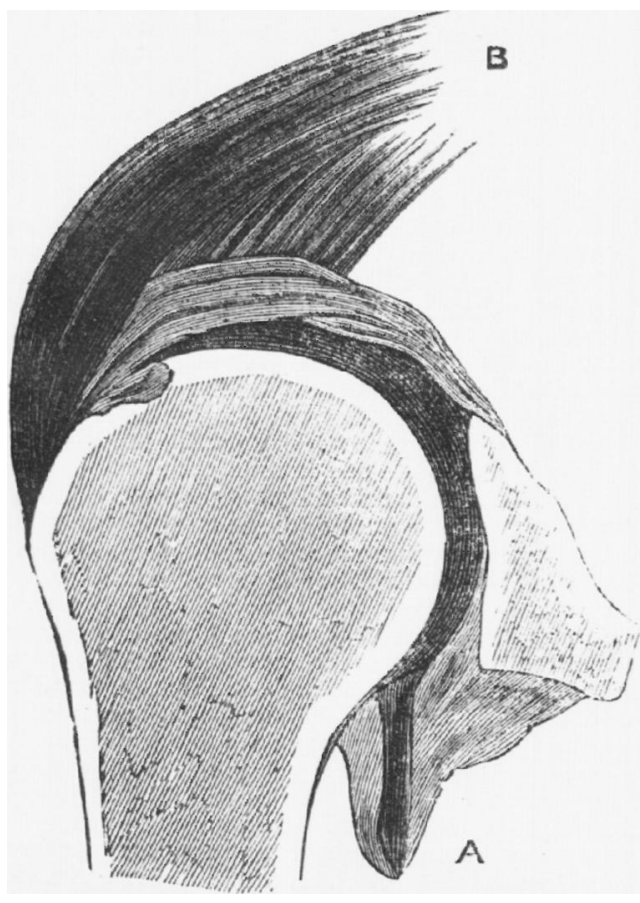

Fig. 1.

Section of shoulder-joint. $\}$ Drawn from specimen.

A. Fold of capsular ligament. . Supra-spinatus muscio inserted into

Now comes the question: In what structures do the changes occur which cause this loss of function? I believe that, as a rule, they are to be found in the capsular ligament and the synovial membrane; less frequently in the matting together of tendons. All the large joints have capsular ligaments; the shoulder and hip decidedly so; the knee, ankle, elbow, wrist, fingers, and toes have strong lateral ligaments, and the parts between these completed by thinner bands of tissue, called anterior and posterior ligaments. For all practical purposes we may consider these as capsular ligaments, with laterally thickened bands. On dissecting these joints and then moving the limb, it is found that the capsule either folds itself in various diroctions like purse, according to the movements of the joint, or it is drewn out of the way by the muscles inserted around the articulation. Iot me refer to the shoulder-joint. The capoular ligament is attached round the margin of the glenoid cavity, and to the anatomical neck of the humerus. It is very lax, 00 much 80 , that when all the muscles are removed, the head of the humerus can be drawn about an inch away from the scapula, without laceration of the capsule. All the muscles inserted into the tuberosities send a few fibres into the capsule; when either of these muscles act, the capsular membrane, instead of folding anyhow, is drawn out of the way before the bone (Fig. 1). If it folded anyhow, it might possibly get nipped between the bones, or it might get creased the wrong way, and so impair movement. This nipping is especially likely to happen at the back of the elbow, between the olecranon process and its fossa. The same rule holds good, I believe, in all the joints of the body (Fig. 2). I have examined most of them, and find it to be so. The importance of the fact is this. If tho joint be moved in certain directions by its muscles, the capsule is drawn out of the way, or folds in such a manner that the morements are not interfered with. If it is moved passively, or by violence, the capsule is not drawn out of the way, and does not necessarily fold

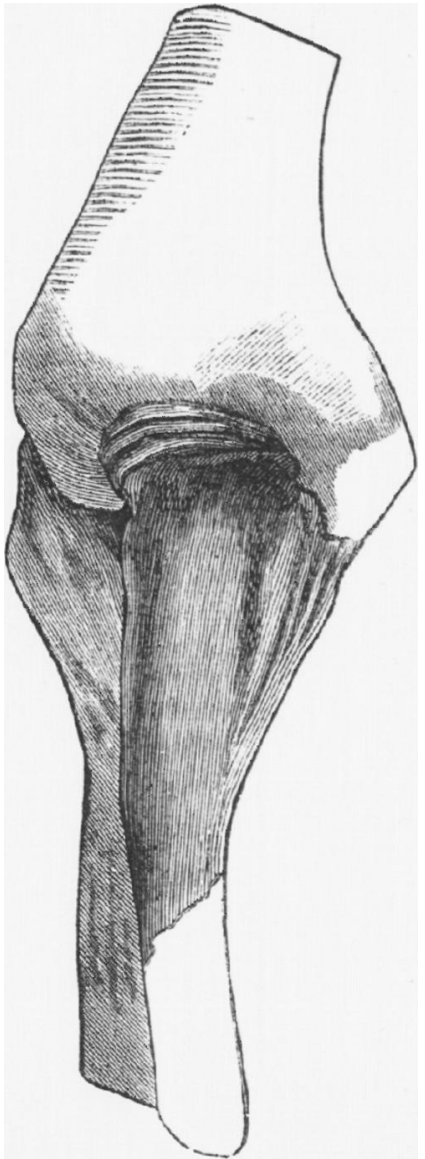

Fig. 2.

Elbow-joint exteuded; irregular fuld of posterior ligament.

in the right direction ; it often does so, but often not. If it is at all sticky from fibrinous effusion, or thickened from the ame cause, the probability is that the folding would be irregular, and the joint-movements correspondingly limited and painful, and as long as one worked it passively, this would continue. I have often noticed myself, after a fall or a blow, a species of discomfort in a joint, which has only passed off after working it round several times. This appears to me to be due to a false folding of the ligament. When the muscles work the joint, the ligament is unfolded and drawn into its normal position. 
It is a useful, practical plan, in putting up an injury, to tell the patient to move the joint himself; by attempting this ho would not only relax the muscles which perform the antagonistic action, as I learnt from a valued teacher, but, if he were unable to exert power enough to do as he was told, he might still have enough to draw the capsule out of the way and prevent an improper folding. These apparently trivial details will be found on close observation to be of real value. The majority of these adhesions take place as the result of traumatism, or of some inflammatory affection of the joint; singularly enough not 80 often after dislocations as after sprains. In dielocations there is a rent in the capsule, and this makes a drainage opening through which the effused fluids escape. As thes result of the injury blood or lymph gets effused; this distends the capsule. In whatever position the limb is put up, this effusion would settle to the loosest or most dependent part. Take the shoulder again. The arm falls naturally to the side, and is bandaged by the surgeon in that position. (This is not always prudent.) As a consequence the lower part of the capsule would be loose; into this the fluid gravitates and distends it. As it subsequently becomes absorbed the surfaces of the pouch approximate each other, and, if left at rest, become bound together, either by direct fusion of their surfaces or by the intervention of organised bands of lymph.

Adhesions are frequently seen without evidence of change in the memhrane or cartilage close to them. We all know, as practical surgeons, that in shoulder ankylosis the greatest difficulty is experienced in raising the arm. I have dissected one of these joints in which ankylosis of some considerable standing existed After dividing all the muscles which depress the arm, I found myself unable to raise the limb, and on careful examination found this was caused by a fusion of the contiguous surfaces of the lower part of the capsular ligament, with its contained oynovial sac. On separating these the arm was easily raised; the rest of the joint was sound.

This fold is sometimes an; inch long, and may be even more than that, so you can easily imagine that in many cases great force must be exerted to tear it asunder. The more recent the adhesion, the more capable it is of being stretched; as it increases in age, like all new flbrous tissue, it becomes tougher, and also has a tendency to contract. Great force is then required to rupture it.

I had a case ahout two months ago, in which, though the patient was under the influence of chloroform, I could hardly rupture the adhesion. By exerting all my force-I am endoweil with more than the average amount-the adhesion ruptured with a loud report. One of our resident officers who was giving the anæesthetic and the students thought the bone was fractured this, however, was not the case. Very little inflammatory disturbance followed, and the movements are now almost normal.

Adhesions may also take place outside the capsule; these are usually the result of rheumatic affections, or are caused by inflammation which has spread from without. The tendons round a joint may also become matted together or fused with the capsule or other parts, and thus impair function. I will tell you another anecdote.

Some years ago I possessed a hunter that had seen his best days, what is commonly called "an old screw"-screwed about the tendons of the forelegs. One day he took a big fence with me, just flinched for a minute as he pitched, but finished the day's work without a sign of lameness. The next day the leg was swollen, and he was evidently suffering from a strain of a tendon. He was treated carefully with cold water bandages until the swelling subsided, and was then prescribed gentle exercise. IIe simply hobbled along. Then I tried riding him, and once or twice in a half-hearted way attempted to trot or canter, thinking it might be stiffness which would wear off, though I did not quite understand the pathology. The result was painful to both the horse and myself. After some weeks I sold him, as I thought, permanently lame. In a very short time the horse was to be seen careering over the country without a sign of lameness. On inquiring the treatment, it turned out to be the whip again. I was somewhat annoyed not to have tried such a simple remedy more effectually ; but I daresay if one had seen the treatment, one would have called the man a brute, though it was a cruel kindness in the long run.

A short time afterwards I had the opportunity of dissecting a horse's leg which had a precisely similar history. Between the flexor tendons were some long, string-like adhesions, evidently stretched long enough not to interfere with movement. At a part lower down was a small patch of soft adhesions, easily separated, and then the tendons worked freely on each other. It seemed to me probable that when the horse started every day ho went lame until these soft adhesions gave way, and then the lameness disappeared. This corresponded with the actual history, the lameness was always more marked after rest, but the whip being applied more freely counteracted this. It is the strain on the adhesion and the loss of mobility that cause the lameness, not the friction of the roughened surfaces. Cases similar to this are not uncommon in man. I had the opportunity of vivisecting one such.

The patient had an incised wound just above the wrist. As the result, the ulnar nerve and flexor carpi ulnaris tendon became bound down to the deeper parts by fibrous tissue. Fxcruciating pain resulted on any movement of the wrist, and even without this. I had on two occasions to separate the nerve and tendon from the deeper parts, and finally the nerve remained detached and the pain was cured. Tho tendon still has a tendency to contract adhesions. The man works, but says he always starts stiff, but that soon wears off. "It is better on Saturday night than Monday morning." The Sunday's rest always makes the part more stiff and painful. Probably, if he rested long enough, the tendon would become fixed again and the wrist movement impaired. The following case is also very instructive.

A. F., aged 26, came to me last winter, complaining of pain, tenderness, and some swelling below and to the inner side of the left knee. Six weeks before, while playing football, he kicked sideways at the ball, with the left leg, at the same time one of his opponents also kicked at it ; their legs crossed, and $\mathrm{F}$. felt a sharp pain in the inner side of the knee. The part swelled, he lay in bed for a fortnight, and was then allowed to get about. After another week or ten days he could walk end run all right, and then played football again. He found that he could not "foick a ball" out of the scrimmage with his left leg (that is, hook the ball out sideways with his foot), any attempt to do 80 causing great pain. After a week or two he had a bad fall with a man on his back, and now comes the interesting part. He felt a sharp pain for a minute or two, and, when that had passed of, the old pain had disappeared, and he thought he was well. The part swelled in the evening, and, when I saw him two days afterwards, there was slight synovitis, and a tender œdematous spot below and to the inner side of the head of the tibia - the original seat of pain. It seemed to me that he had strained the tendons at that spot weeks before; as the result, adhesions formed; these were broken by the fall, and fresh effusion appeared. By gentle exercise and friction he soon recovered complete use of the leg.

Now we should consider the history and symptoms of these cases: a knowledge of the anatomy or pathology is of no use unless we can recognise their external indications. The majority have a history of this sort. They have had a fall, or a blow, or a strain of a joint. If the injury is very severe, there is probably immediate and continuous loss of function. If less severe, tho loss of movement may come on gradually and get worse and worse until it is completely abolished. Or, again, there may be a rheumatic, strumous, or specific diathesis, and a slight injury or even exposure to cold may bring on a similar state of things.

In the early stages rest and soothing treatment should be adopted; but if the case goes on to ankylosis, "bone-setting" may be required. I will describe a case.

M. N., aged 45, a strong, healthy woman, with no inherited or acquired predisposition to disease, sprained her right ankle about four months before I saw her. It swelled very much. The medical man who saw the case very properly placed it in splints, and at the end of six weeks left them off, and recommended very careful and gentle exercise, and friction with some liniment. After walking or hobbling, the ankle swelled and became more painful, and walking itself caused her pain. The splints were then reapplied for fourteen days, when she was again to try exercise; the same pain and swelling ensued. Disease of the joint was then hinted at, and, as is usual, all the patient's friends passed their opinion on her case, that which found most favour being the idea that a " bone was out." This opinion she suggested to me at the commencement of our interview. The ankle was slightly thickened, but distinctly white and cold; all the bones were in their normal position, pressure caused no pain, stamping caused no pain; the foot was fixed at a right angle to the leg.

On careful and very gentle examination, slight movement could be detected, but muscular spasm and pain ensued if the movemonts 
were done at all roughly, and the joint then appeared more fixed, in fact, absolutely so. The diagnosis was clear-fibrous adhesions within or around the joint.

I should also call attention to the fact that the knee of the other leg was distended with fluid, which had appeared subsequent to her attempts at locomotion, evidently due to the increased strain thrown on it by her "dot and go one" style.

Distracting her attention, I gave a sudden wrench to the ankle ; a loud report ensued. In a few minutes, after the pain had passed off, the patient could move the joint freely quite two-thirds of its normal movement, and she walked across the room comparatively well. She then said: "I thought the bone was out;" she was firmly persuaded she had heard it go in. It took me five minutes' hard talking to convince her that such was not the case, and then she was only convinced to the extent the gentler sex are "against their will." I did not wonder then that bone-setters often saved themselves the trouble of explaining, but let the patients think as they pleased. This case went on rapidly to complete recovery as far as the ankle was concerned. She has had occasion to consult me again for her knee, which has remained weak.

This case had been treated quite correctly in the early stages, but, as in the case of my father's horse, the whip had not been applied, and so the lameness continued.

There is another side to this question. W. S., aged 24 , a healthy countryman, sprained his ankle badly. He saw a medical man, who told him to bandage it. He only lay up for four days, and then walked about. As the result the ankle became worse and worse, and when I saw him about seven months after the accident, there was suppuration and disorganisation of the joint, and amputation had to be resorted to. Successful treatment of these cases lies midway between the $t w o$, first a period of rest, and then exercise. The great secret of success lies in judging the exact period at which the one should be changed for the other. No hardand-fast rule can be established.

In nearly all cases of fibrous ankylosis we find muscular spasm. This alone, in the absence of inflammatory symptoms, or those of new growths or constitutional disease, is sufficient indication for "bone-setting." Many surgeons think it impossible to mistake these affections for each other; there is little dunger of doing so when the inflammation or the new growth is well marked, but in their earlier and less acute stages the diagnosis is far from easy. As a rule, I find that the more spasm the slighter are the adhesions.

When the ankylosis is bony, the disense must have existed for a long time, and, the joint being completely fixed, spasmodic action of the muscles is not required to check the movements; they are abolished. The muscles, therefore, waste and undergo fatty degeneration. Pain is a most misleading symptom. The most hysterical, painful case I ever had to deal with was cured by one slight wrench, without even synovitis following it. There was a distinct crack, and the patient immediately moved the joint freely and painlessly, and was extremely grateful. Patients suffering from hysteria pure and simple are not so. In the case of one small adhesion the strain is concentrated on one spot, and consequently is more severely felt. If you pinch a small piece of skin between your finger and thumb nails, acute pain is felt. Pinch a large piece with three times the force, and not half the pain is experienced. Again, pull a single hair of your head, and notice the difference between the pain and that caused by pulling a number together. So it is with the adhesion.

On making an examination of a knee-joint in the dissectingroom at Bristol, 1 found one small tough adhesion, about the size of a fine piece of twine, between the internal condyle and the back of the tibial spine. In this case the adhesion was stretched long enough not to interfere with movement. My patient, a nervous, sensitive woman, had not the pluck to do so, and consequently suffered severely until the adhesion was ruptured.

Now comes the question, Where is the pain felt? Hilton, in his interesting book on Rest and Pain, states that the nerres which supply a joint are branches of those which supply the muscles acting on that joint, and also the skin over it. I will give you a case in point. A man fell over a plank on to his shoulder, bruising the upper part of the joint. Great pain was felt, but only on his attempts to abduct the arm. On passively moving the limb in that direction a soft crepitus could be detected. This movement was also painful. The interesting point is, the pain was not referred to the joint, but to the scapula and side of the neck-the course of the suprascapular nerve. This nerve supplies the upper part of the joint and the supraspinatus muscle which abducts the limb. Pain was also felt on deep pressure orer the head of the bone. Sometimes the pain is experienced immediately over the affected spot, either case being explained by Hilton's theory. I will now refer briefly to some of the more frequent and troublesome complications.

All cases of fibrous ankylosis cannot be cured by one wrench: it is exceptional to find them so simple. When one does get a case it is an easy way of scoring a brilliant result. Cases vary much: each must be judged on its own merits. Those most amenable to treatment are due to simple traumatisms in healthy subjects. These recover with marvellous rapidity, and, singular at first sight to relate, it often happens that the longer the ankylosis has existed, the simpler is the cure. The first wrench may require greater force, but as a rule there is less subsequent disturbance in the joint. In these cases the joint, at least that part between the adhesions, has had time to recover its tone, and the adhesions being simple fibrous cords, are just snapped across, and the joint is free. Not infrequently, however, the strain on the adhesions has produced a chronic aynovitis, which obscures the primary cause.

Rheumatism is one of the most troublesome complications: erery change of weather produces evidence of the constitutional affection in the weakened part, and this of itself contra-indicates movement. I have a troublesome case under my care at the present time. A young man, aged 24, consulted me in February of this year for stiffness of the right hip. Ten years ago this hip was crushed by a waggon wheel, and he is said to have sustained a fracture in that region. He completely recovered from that accident, and has won athletic races since. About seven years ago, he went to Australia. In March of last year he had a bad attack of rheumutic fever, which lasted seven weeks. He was in the bush, and was only seen once by a doctor. After this he found his right hip stiff; he was unable to bend it, ride on horseback, or follow his occupation with any comfort. He went into hospital in Sydney in August. While there he was treated by extension and blisters to the part. The extension caused him great pain. While in hospital he contracted typhoid fever. Ife left on December 3rd and returned to Fngland. When I saw him in February there was complete loss of function of the hip-joint. Marked lordosis occurred on any attempt to straighten the leg; and very marked muscular spasm existed, especially of the adductor longus. The loss of movement was so complete, that had it not been for the history and the muscular spasm, I should have considered the ankylosis bony. The right buttock and thigh were atrophied, the latter measuring two inches less in circumference than its fellow. If the patient put both heels to the ground, he measured two inches less in height than when standing on the left leg only. The thigh was fixed at an angle of $140^{\circ}$ with the body. There was a very marked rheumatic history in the family, consequently my prognosis was guardı $d$.

On producing complete muscular relnxation by chloroform, the very slightest pressure enabled me to fully extend the leg, and move it freely in all directions. Some soft adhesions were felt to give way in the process. As the adhesions were so easily separated I hoped he would soon regain the full use of the limb, but the rheumatic tendency has retarded recovery. The weather has been exceptionally severe, and at every fresh change both the patient and his fatler have had twinges of rheumatism. The fact of the father suffering at the same time has made the son more patient under the careful and tedious treatment required. The latter gets pain only in the weak hip, very rarely in the knee of the same leg. Whenever the rheumatism appears, muscular spasm ensues, and on attempting passive movements the lumbar rertebrae arch backwards and forwards instead of the normal novement at the hip-joint. By careful treatment the patient, in spite of these drawbucks, is now able to sit confortably in a saddle, rise up and down to an imaginary trot, throw his leg accoss the saddle with ease, and I am hopefil that during the summer he will regain almost if not complete use of the joint.

Struma and syplitis are complications requiring great care. If the constitution is really bnd, the less one meddles with the case the better. Slight attempts only at movement may be made under chloroform. Many cases of so-called strumous joint-disease depend on a traumatism occurring in a subject debilituted by bad food and improper hygienic surroundings, though they may possibly have inherited a good constitution. In such cases the general health should first be attended to, and when that has been improved, movements may be attempted. The same rule holds good when syphilis is the complication. 
Now comes the question of treatment. We cannot do better than refer to my text. The horse had a suppurating kneo-joint; it was turned out to grass for three months; before the whip was applied the knee was the same size as the other, and free from inflammation.

The principal symptoms of cases suitable for forcible movements may be summed up as follows. Loss of motion and muscular spasm, especially on rough handling. On very gentle manipulation slight movement can be ;felt, and that perfectly smooth. Pain on more forcible movement, pain at night, pain on waking in the morning, pain at change of weather, pain on jarring the limb, absence of inflammation, extra coldness of the part, very slight thickening only (if there is much it should be lessened by rest or gentle exercise, blisters and absorbent application, with light friction), the lapse of some weeks before forcible movements are attempted. In the earlier stages forcible movements produce a large amount of fresh effusion, and possibly inflammatory disturbance.

I remember a case some years ago in which I yielded rather to the patient's solicitations, and moved a joint freely in the earlier stage. A large amount of effusion was poured out, and it was only by very careful treatment that suppuration was prerented.

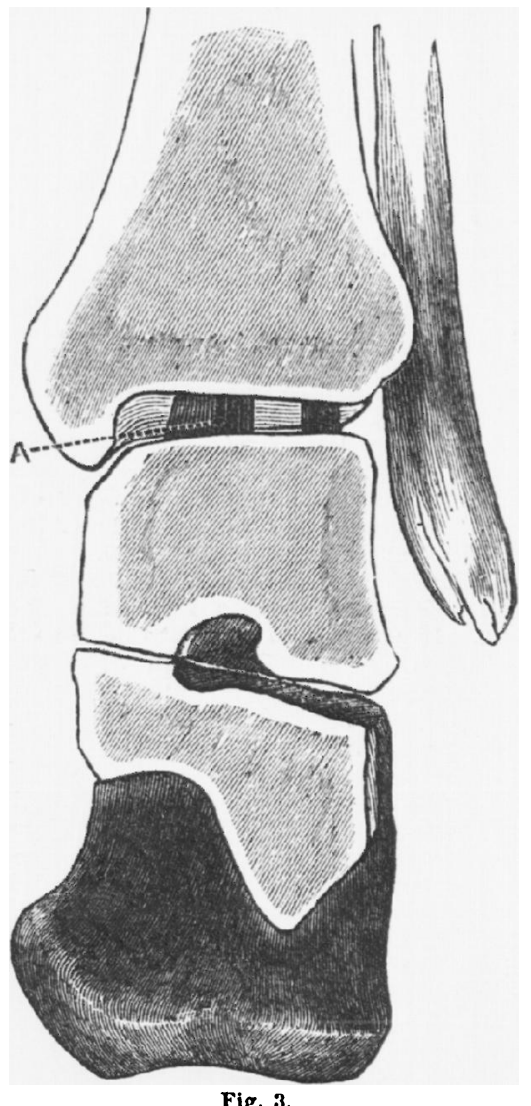

Fig. 3.

Section of ankle-joint showing adhesions (A) between tibia and astragalus rest of cartilage healthy. No. 1797. College of Surgenns Museum. This diagram was copied from a rough sketch taken from the specimen.

In the earliest stages, that is, directly after an injury, perfect rest should be prescribed. In a few days, if the patient be fairly healthy, absorption of some of the effused fluids will have taken place, and a plastic material remains which can be stretched or moulded by gentle passive movements; these also favour absorption, and should be combined with very gentle friction, remembering the axiom of Ilippocrates that hard rubbing binds, soft rubbing loosens. The rubbing should always be done in a centripetal direction. Absorbent remedies may be combined with this treatment. If the case does not progress satisfactorily, or has not come under observation sufficiently early, forcible movements may be required to rupture the adhesions. In suitable cases force should not be spared; in one of mine I had to exert all my strength. I felt that, even if the bone was fractured, the patient would be no worse off in the long run than if he were allowed to remain as he was. I once saw a humerus fractured by a prominent member of our profession in his attempts to rupture adhesions in the elbow-joint. The patient had a better arm than before operation.

After the adhesions have been ruptured, a day or two of rest should be prescribed, with cooling lotions, and then gentle exercises, actire as well as passive. Here is a diagram of a case in which considerable force would have to be exerted to tear through the adhesion.

In cases in which the cartilage has been partially destroyed there may still be movement ; the cartilage is replaced by a fibrous material, which fulfils its purpose. I remember a case of compound comminuted fracture of the knec-joint, which was treated in the Bristol General Hospital. I removed several pieces of cartilage from the joint, and yet that patient recovered with a fair amount of movement. There are sereral specimens in the College of Surgeons Museum which show the replacement of cartilage by fibrous tissue. It is not at all uncommon to find similar evidence with free joint-movement in the dissecting-room ; therefore, destruction of cartilage is not sufficient reason of itself to contraindicate forcible movements. Such evidence, howerer, should

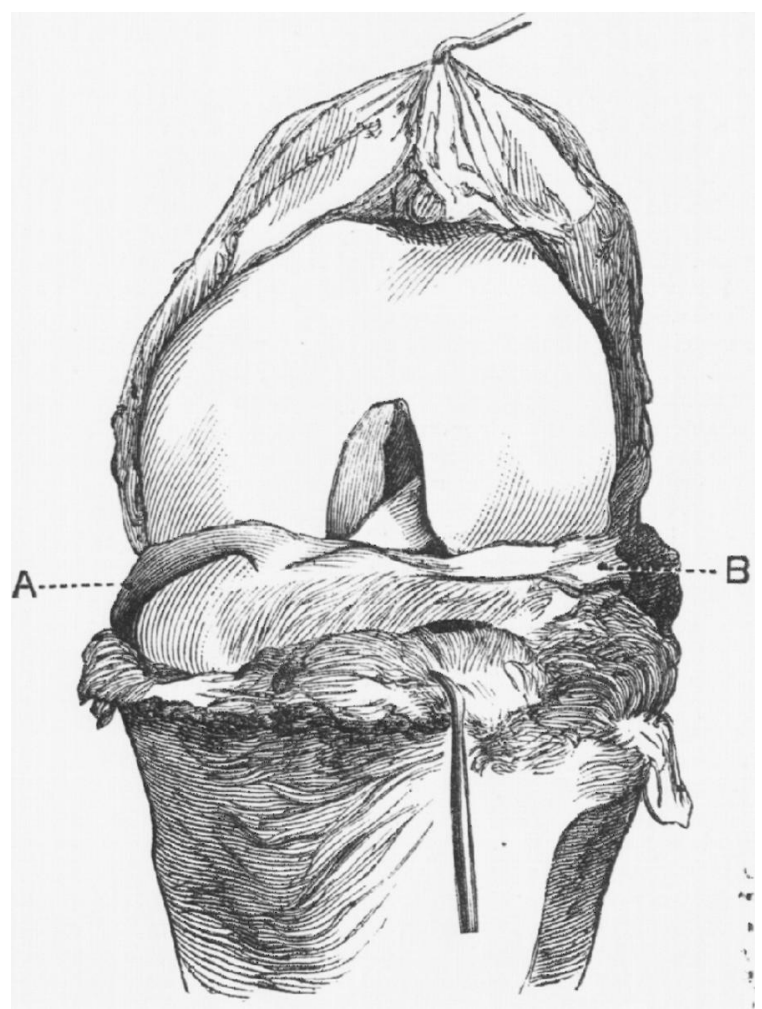

Fig. 4.

Front view of flexed left kneo-joint. A Internal, B External semilunar cartilages in their normal positiou. Skin reflected from femur and tibia. make us careful as to the amount each case could safely bear, and also particularly careful in the after-treatment. Cartilage itself, as Hunter has told us, is capable of taking on adhesions, without marked change in its structure. Specimen 1797 in the College of Surgeons Museum shows this well (Fig. 3). The cartilage close to the adhesion is smooth and quite unchanged to the naked eye.

Now we come to another class of cases-internal derangements. Many of these are caused by loose bodies in the joints, which may become nipped between the bones. These have special symptoms peculiar to them, and should be removed as soon as possible.

The knee-joint is the most common site of these derangements. It is the most complicated joint in the body. Besides flexion and extension, when the knee is flexed, rotation of the tibia on the femur is permitted. When this is carried to an abnormal degree, there may ensue either a subluxation of the condyle of the femur, or a displacement of a semilunar cartilage. The internal carti, 
lage, as you will see by this diagram, is the straighter and longer: the outer is smaller and more circular. The inner, besides being attached to the front and back of the tibial spine, is attached all round the inner half of the head of the tibia by fibrous bands, as well as to the internal lateral ligament. Sometimes this cartilage becomes displaced and nipped between the bones, or it may slip into the notch between the condyles of the femur. The external cartilage is not attached round the head of the tibia, and consequently shifts its position easily, and follows the condyle, and is less frequently displaced than the internal. I will quote a case of displacement of the internal cartilage, and then explain. H. S., aged 25 , sprained his knee at football in January, 1886. Synovitis followed, but subsided after some weeks. He regained full use of the joint, but a feeling of weakness remained, for which he wore an elastic knee-cap. In March, 1887, he slipped on the snow, and felt a sharp pain on the inner side of the knee. His leg was flexed and fixed in that position, but on pressing his hand firmly on the inner side of the knee something seemed to slip, and he could then flex and extend the joint freely. The knee, however, swelled and became painful. When I saw him four days after the accident he had slight effusion into the joint; there was œdema and marked tenderness over the upper part of the tibia, at its junction with the cartilage. No pain was experienced on flexing the knee, but only when pressure was throwa on the internal lateral ligament.

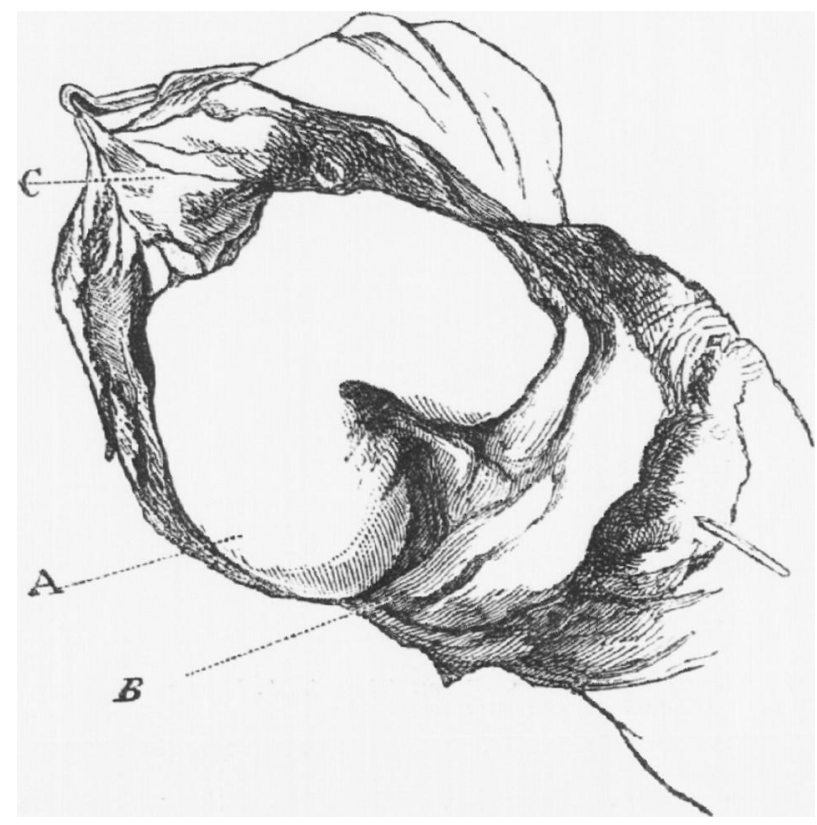

Pive. \%.

The same joint as in Fig. 4: lateral ligainents intact. A. Internal condyle of femur over-riding internal semilunar cartilage B. Knee partially fexed; femur rotater in; tibia rotuted out; tibia abducted on femur. C. Patella refiected.

Slight displacement of the internal semilunar cartilage, with strain of the internal lateral ligament, was diagnosed. $\quad$ A felt splint was applied, in the hope that the cartilage would becomeattached again. The synovitis soondisappeared, and the leg becamestronger. At the end of five weeks the patient, who was very anxious to play cricket, said he was quite well, and, contrary to my orders, played. In turning for a quick run, he felt a sharp pain again in - the old site. The knee was locked, and could not be replaced without help, and then only after great difficulty had been experienced. This has happened several times since, and I expect to have to operate to fix the cartilage in its proper position. In this case the sprain of 1886 had probably weakened the internal lateral ligament and the fibres which attuch the curtilage to the head of the tibia (Fig. 4). In that particular moveme'nt of turning tharply, and pushing off with the foot--nearly all the cases I have met with have been caused in a somprobs similar manner-there is a double rotation and abduction. The femur rot ates inwards, the sibia outwards, at the same time, thw iuternal lateral lignment be- ing loose, the bones are allowed to separate, and the tibia is abducted (Fig. 5). All these morements, done sharply and with violence. may cause the condyle to shoot over the edge of the cartilage, and thus become locked; this would be a subluxation. Sometimes not only this happens, but the cartilage gets detached and displaced inwards. While examining this point in the dissecting room one day, I was doing these movements forcibly on a subject. and the cartilage became separated and displaced before my eyes. It happens thus. If the knee is flexed, the back part of the condyle of the femur, when rotated inwards, tends to push the posterior part of the cartilage in the same direction: if the tibia be now rotated outwards, the front part of the cartilage is unsupported by bone, its anterior attachment is carried out with the tibia, and great strain is then thrown on its fibrous attachments to the head of that bone; if these give way, the arc is straightened and the tension relieved, and the cartilage slips outwards. If the bones are much separated, and the movement done suddenly, the cartilage may shoot clean under the condyle into the notch, and lodge there (Fig. 6). When all the fibrous bands are torn, this accident is not unlikely to happen; eren when it does, the cartilage can be replaced by extreme flexion of the knee, with subsequent rotations. Mr. Gray, our assiatant demonstrator of anatomy, who kindly took some photographs for me, complained that now the cartilage was separated, he could not place the bones in the position de-

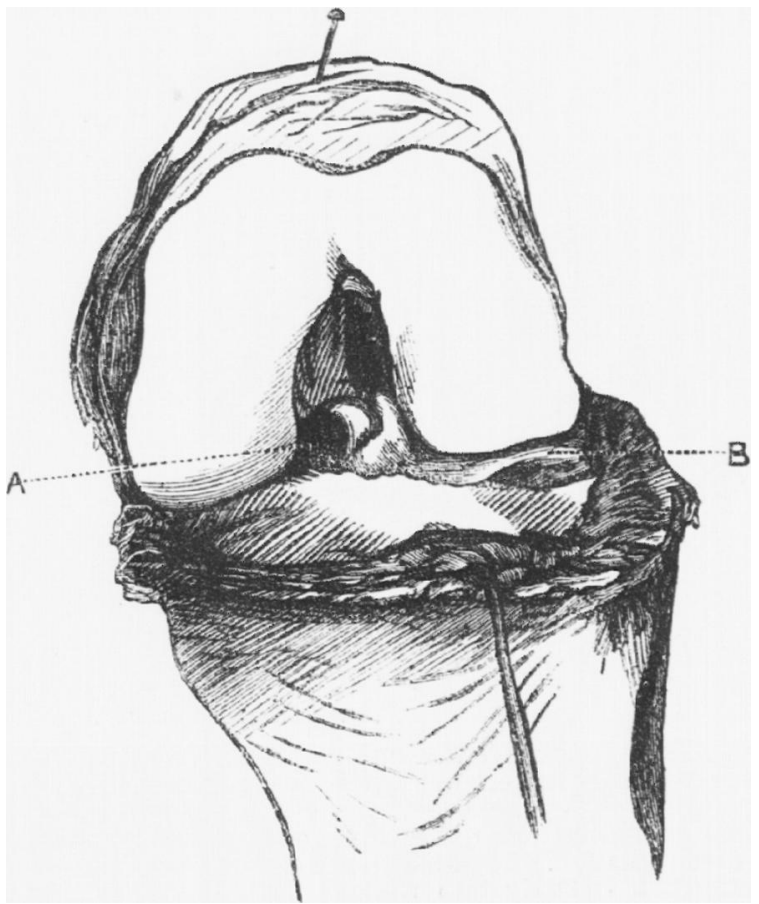

Fig. 6.

A. Intertual semilunix (eutilage displaced between internal condylo of iemur and auterior crucial ligament. Tlbia abducted and rotateil ouc uardly iu consequence. B. Exterual semilunar cartilage.

scribed without the cartilage slipping between the condyles. Mr. Howard Marsh, in Diseases of Joints, refers to three of these cuses dissected and described by other surgeons.

When the cartilage is completely displaced between the condyles, the joint movements are less interfered with than when the displacement is partial. In other cases of internal derangenents. the fat or synovial fringes, especially when thickened or cedematous, nay become displacel and nipped between the bones.

I will describe another case, with its explanation-a hip case: J. II., aged 17, was getting out of a donkey cart when the animal moved on. The patient's right leg slipped on the inside of the shaft, and the left came to the ground. His right thigh was thus forcibly abducted and slightly flexed. He then found that he was unable to walk properly or stoop; he was a very poor man, and said : "If I saw a shilling on the ground I could not pick it up." He hobbled with difficulty into my room about forty-six hours after t!l: alcilent. All simple remedies had becn triod, but 
they were of no avail. His leg had the everted, abducted, lengthened appearance seen in subpubic dislocation of the hip. The bones were, however, in their normal relations, there was marked muscular spasm, so that I came to the conclusion it was a disarrangement of something : what I did not exactly know. Acting on the principle that if morement in one direction is particularly painful the opposite movement should be carried to its full extent, and then the painful movement tried quickly, and finding that attempts at extension caused him most pain, I flexed the leg fully on the abdomen and rapidly extended it. The latter movement could then be performed quite freely and painlessly. The patient worked the leg himself, stooped with the greatest ease, and walked round the room in his usual manner. I shall not forget his surprised look as he worked his leg up and down, and said: "Why, it's all right now, Sir." A bone-setter could easily have done this, or an accidental fall might have had the same effect. $\Delta s$ it is, a legitimate member of the profession has the credit.

The case puzzled me. I consulted authorities, and all the explanation I could find was that a muscle or tendon might be displaced. On doing the movement forcibly in the dissecting-room, profession from charges of ignorance or carelessness. Ofton one feels and knows the truth of these charges. There is a tendency to look on these cases as hysterical or beyond cure. For my own part, I can only say that every year I meet with less hysteria and more definite pathological lesions. Varying degrees of muscular power are required in the treatment, from a force of a few ounces to humour and overcome the spasm of a muscle, to a force of possibly a couple of hundred pounds or even more to rupture dense bands of fibrous tissue.

We should be prepared for any emergency. Accidents may happen in spite of the greatest care and forethought. We should not, for a very remote danger of bad consequences, condemn a large number of individuals to a life-long suffering; for these patients get pain as well as impairment of function. I rarely see inflammatory disturbance follow these manipulations if ordinary care be used. If acute suppuration of a joint should set in, I feel that, thanks to Sir Joseph Lister, we have a very powerful ally at our backs in the antiseptic treatment, an ally that robs these cases of their great dangers to life or limb. I have had the treatment of several cases of suppurating joints, in which not only the patients' life and limb were saved, but :

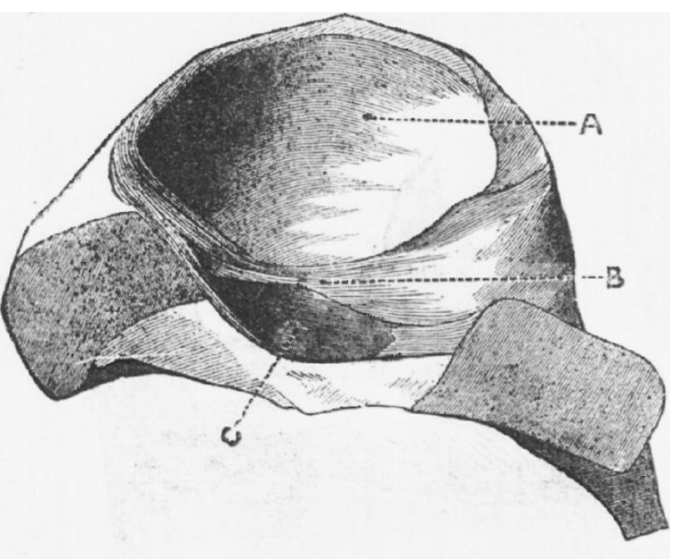

Fig. 7 .

A. Acetabulum. B. Transverse ligament. C. Acetabular notc'1. no muscle could be made to disarrange itself ; there is no particular bony prominence to keep out of its place any muscle which may have slipped. No muscle could have been ruptured, as the man did all the movements quite freely and painlessly immediately after manipulation. Then I tried the capsule, but the head of the femur fits too closely into the acetabulum to allow that to be nipped, and a simple abnormal folding would not cause the leg to be fixed. The ligamentum teres was then tried. Professor Humphry, in his interesting book on the skeleton, states that when the thigh is abducted in the erect posture the ligamentum teres is compressed into the lower part of the acetabulum by the head of the femur (Fig. 7). In extreme abduction tle ligament and the fatty tissue at its base is driven under the transverse. ligament. On doing this movement forcibly and quickly, the ligamentum teree was found to be nipped under the transverse ligament, and this maintained the deformity. On flexing the thigh fully the ligament is drawn back into the joint, and remains there when the leg is subsequently extended. I believe this to be the explanation of my case. The abnormal position was probably maintained by reflex spasm of the surrounding muscles (Fig. 8).

I regret that time will not allow me to enter more fully into the subject; it is most complicated. Bone-setters gain their harvest because we, the legitimate practitioners, too frequently consider the necessary details and delicate manipulations beneath our notice. The loss of function of one joint is often of os much importance to the patient as the loss of a limb. On numerous occasions I have had to defend the reputation of members of our

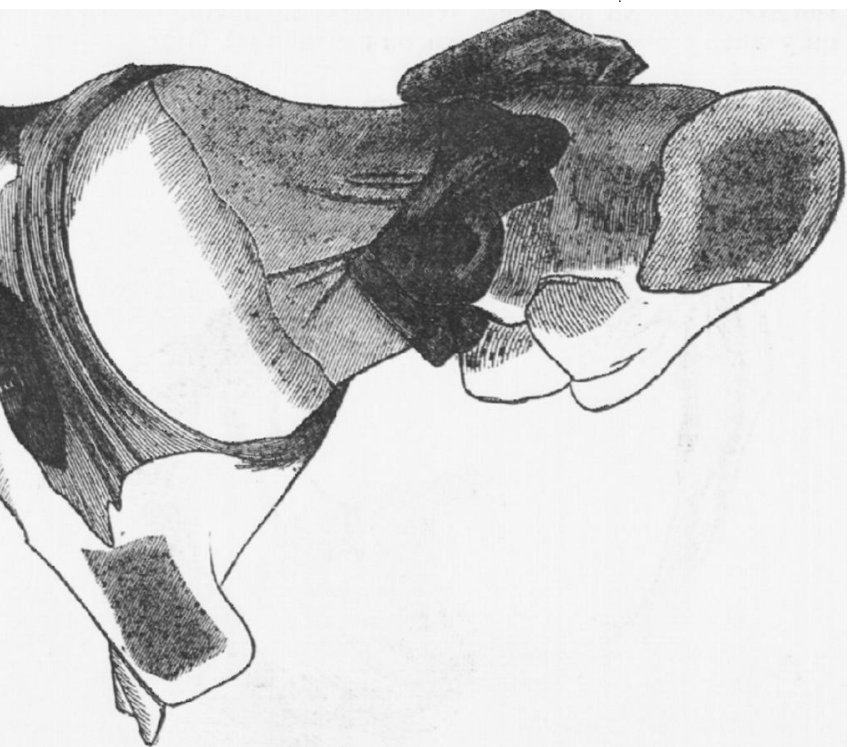

emur in acetabulum. Femur abducted. A. Ligamentum teres protruding under transverse ligament.

certain amount of morement as well. In one case the subsequent movement was jerfect.

We must not forget that if we do not adopt this practical and legitimate treatment ourselves, we run a great risk of being instructed in our profession by men we contemptuously speak of as "quacks."

The diagrams were drawn from prepared specimens and from photographs taken for me by Messrs. F. Calder and T. C. Gray, of the Bristol Medical School, to whom and to the artist I take this opportunity of expressing my thanks.

Bequasts to Dublin Hospitals.-The late Mr. Wm. Bannon has left several bequests to Dublin hospitals. Amongst those are the Meath and Sir Patrick Dun's, which will each receive about $£ 6,000$.

The RAILway Death-RATE.-The return of railway accidents. for the year 1887 compares unfavourably, in more ways than one, with that of its predecessor. There were during the year 25 passengers killed as compared with 8 killed in 1886, and these, it should be pointed out, occurred all on one line. There were 538 injured from various causes against 615 in the preceding year, while 8 servants of companies were killed and 109 injured as against 4 and 81 respectively from the same causes in the vear before, rendering the total list of deaths from collisions and accidents 33 and injuries 647 , whereas only 12 were killed, though 696 were injured, in 1886. 